\title{
Predictive Value of Betatrophin for Determining the Cardiovascular Risks of Obese Individuals
}

\author{
Nazli Haciagaoglu ${ }^{1}$, Huseyin Cetin ${ }^{1}$, Ozlem Hurmeydan ${ }^{2}$ and Engin Ersin Simsek ${ }^{1}$ \\ ${ }^{1}$ Department of Family Medicine, University of Health Sciences, Kartal Dr. Lutfi Kirdar City Hospital, Turkey \\ ${ }^{2}$ Department of Biochemistry, University of Health Sciences, Kartal Dr. Lutfi Kirdar City Hospital, Turkey
}

\begin{abstract}
Objective: To determine cardiovascular risk factors, calculate cardiovascular risk, and the value of betatrophin, a novel biomarker in predicting the risk of cardiovascular disease (CVD) in obese individuals.

Study Design: Cross-sectional and descriptive study.

Place and Duration of Study: University of Health Sciences, Kartal Dr. Lutfi Kırdar City Hospital, Turkey, from August to November 2019.

Methodology: Three hundred and sixty-three patients sociodemographic information was obtained, anthropometric measurements were made, and routine laboratory examinations were taken for obesity. In addition, betatrophin was studied from the samples collected and stored under appropriate conditions. The risk of CVD development in the patients was calculated using Framingham and PRCAE risk calculation systems.

Results: The median betatrophin level of the participants was 745.8 (636.3-935.7) ng/L. A significant relationship was found between Framingham sub-risk groups and betatrophin level $(p=0.049)$. Moreover, a significant relationship was also found, especially between the medium-risk group and the high-risk group $(p=0.029)$. A significant correlation was found between the triglyceride and the betatrophin levels $(p=0.001, r=-0.166)$. No relation was found between betatrophin level and risk score in the PRCAE sub-risk groups.

Conclusion: Its significant relationship with the risk groups determined by the Framingham scoring system and triglyceride level is promising for betatrophin to be used as a new biomarker in predicting the CVD risk.
\end{abstract}

Key Words: Betatrophin, Framingham score, Cardiovascular disease, Obesity, Risk.

How to cite this article: Haciagaoglu N, Cetin H, Hurmeydan O, Simsek EE. Predictive Value of Betatrophin for Determining the Cardiovascular Risks of Obese Individuals. J Coll Physicians Surg Pak 2021; 31(02):177-181.

\section{INTRODUCTION}

Although obesity is a complex and multifactorial disease, CVD, hypertension, hyperlipidemia, cerebrovascular disease, various cancers, obstructive sleep apnea, fatty liver, gastroesophageal reflux, polycystic ovary syndrome (PCOS), depression, and type 2 diabetes mellitus (DM) contribute to the development of many health problems and create a huge burden on the health budgets of societies. ${ }^{1}$ Obesity worsens most cardiovascular risk factors such as plasma lipids, blood pressure, glucose, and negatively affects systolic and diastolic ventricular function. ${ }^{2}$

CVD is the most common cause of death around the world. World Health Organization reports that the incidence of CVD can be reduced by half with the control of blood pressure, obesity, cholesterol, and smoking. For this reason, individuals with high risk ofCVD should be detected early and protected. ${ }^{3}$

Correspondence to: Dr. Nazli Haciagaoglu, Department of Family Medicine, University of Health Sciences Kartal Dr. Lutfi Kirdar City Hospital, Turkey

E-mail: drnazliunver@gmail.com

Received: October 20, 2020; Revised: January 05, 2021;

Accepted: January 30, 2021

DOI: https://doi.org/10.29271/jcpsp.2021.02.177
Variousscoring systems are used in the calculation of cardiovascular risk. The Framingham system is the most commonly used risk calculation system. The system classifies the 10 -year risk of developing a fatal and non-fatal coronary event as $<10 \%$ low risk, $10-20 \%$ medium risk, and $>20 \%$ high risk. ${ }^{4}$ The American Heart Association and the Turkish Society of Cardiology recommend the use of the pooled risk cohort assesment equation (PRCAE) risk scale. Risk assessment results are considered as $<5 \%$ low risk, $5-7.4 \%$ medium risk, and $\geq 7.5$ high risk. $^{5}$

Betatrophin was first identified in 2004. It was shown to regulate lipase activity in mice and correlate with serum triglyceride levels ${ }^{6}$. Betatrophin plays a role in the regulation of both glucose and triglyceride metabolism ${ }^{7}$. In addition, betatrophin has been associated with many diseases such as gestational diabetes, polycystic ovary syndrome, obesity, nonalcoholic fatty liver disease, and preeclampsia. ${ }^{8}$ A study investigating the relationship between betatrophin level and coronary artery disease (CAD) found its association with CAD. Betatrophin level is thought to be associated with atherosclerotic risk factors such as body mass index (BMI), glycolysed hemoglobin ( $\mathrm{HbAlC}$ ) level, low density lipoprotein (LDL) level, triglyceride level, and smoking. It is thought that the betatrophin level can be used to show the presence of atherosclerotic disease. ${ }^{9}$ 
One of the primary goals of primary healthcare services is to identify risk factors that may cause disease development at an early stage and to combat modifiable factors. This study sought to reveal the relationship between the risks calculated by cardiovascular risk scales of obese individuals and betatrophin level and determine the value of betatrophin in predicting CVD risk.

\section{METHODOLOGY}

This cross-sectional and descriptive study included 363 patients, who applied to University of Health Sciences, Kartal Dr. Lutfi Kırdar City Hospital, Family Medicine Obesity Outpatient Clinic between August and November 2019 for the first time, requested obesity-related examinations, were between the ages of $18-65$, had a $B M I \geq 30$. Patients with a known history of cardiac disease, a history of myocardial infarction, acute coronary syndrome, PCOS, a history of gestational diabetes, and pregnant individuals were excluded.

The patients were seen by the a researcher and an observer, their anamnesis were taken, physical examinations were performed, and height, weight, waistcircumference, hip circumference and blood pressure measurements were made. According to their BMI values, the patients were grouped as class 1 (BMI 30-34.9), class 2 (BMI 35-39.9), and class 3 (BMI $\geq$ 40). ${ }^{10}$ Body analyses of the patients were performed with a JAWON device on empty stomach, without metal and with bare feet. Since two patients included in the study had platinum in their bodies, fat-muscle analysis could not be performed. Fat-muscle analysis was requested in both patients, but could not be measured by the device. Cardiovascular risks of the patients were calculated using the Framingham and PRCAE risk calculation scales. ${ }^{11,12}$ Since there are differences between the societies between cardiovascular risk calculation systems, the current risk was calculated with two separate scoring. The Framingham risk calculation scale via applicable http://reference.medscape.com/calculator/framingham-cardi ovascular-disease-risk site and PRCAE risk calculation scale was accessed via http://clincalc.com/Cardiology/ASCVD/PooledCohort.aspx.

At the beginning of the study, the patients were informed and their consents were obtained. Approval was obtained from the Ethics Committee of the Hospital, with Ethics Committee No. $2019 / 514 / 148 / 31$. The treatments of the patients were arranged according to the risk factors. Cardiology control was recommended for the patients in the high risk group.

After obtaining the consents from the patients who met the inclusion criteria, the blood was centrifuged and taken into eppendorfs and kept under appropriate conditions at $-80{ }^{\circ} \mathrm{C} .{ }^{13}$ After all samples were collected, they were studied in accordance with the procedure with the Andygene brand Human Betatrophin ELISA kit (Catalog No. AD9870Hu). The research kits were provided by the University of Health Sciences Scientific Research Projects Coordinator.

Study data were analysed in SPSS version 21.0 package programme. Descriptive criteria (frequency, percentage, mean, median, standard deviation and 25th percentile-75th percentilevalues) were used in the analyses. Kolmogorov-Smirnov test was applied as normality test. Pearson and Spearman correlation tests were used to evaluate the relationships between continuous variables. Since the data do not show a normal distribution, Kruskal-Wallis and Mann- Whitney U-tests were used to determine differences among groups. As a result of all analyses, a p-value of less than 0.05 was considered significant.

\section{RESULTS}

A total of 363 patients were included in the study; 297 (81.8\%) were females and 66 (18.2\%) were males. Socio-demographic characteristics of the participants are summarised in Table I. In terms of chronic diseases, metabolic syndrome was found in 205 (56.5\%), DM in 117 (32.2\%), prediabetes in 130 (35.8\%), insulin resistance in 277 (76.3\%), hypertension in 169 (46.6\%), hyperlipidemia in 272 (74.9\%), depression in 22 (6.1\%), obstructive sleep apnea in five (1.4\%). In terms of drug use, $123(33.9 \%)$ of the patients used metformin, 36 (9.9\%) other oral antidiabetics, 15 (4.1\%) insulin, 107 (29.5\%) antihypertensive, 27 (7.4\%) antilipolytic agents, and 22 (6.1\%) antidepressants. The mean measured systolic blood pressure of the patients was $122.3 \pm 18.6 \mathrm{mmHg}$ and the mean diastolic blood pressure $75.6 \pm 12.7 \mathrm{mmHg}$. The anthropometric measurements revealed that the mean waist circumference was $117.7 \pm 14.3 \mathrm{~cm}$, with average $\mathrm{BMI} 38.7 \pm 6.5$ $\mathrm{kg} / \mathrm{m}^{2}$, the average body fat mass of $40.7 \pm 9.8 \mathrm{~kg}$, the average body fat percentage of $39.9 \pm 5.1$ and the average lean body mass of $55.4 \pm 11.1 \mathrm{~kg}$. One hundred and twenty-three (33.9\%) of the patients were placed in class 1 obesity, $108(29.7 \%)$ in class 2 and $132(36.4 \%)$ inclass 3.

Table I: Socio-demographic characteristics of the participants.

\begin{tabular}{|l|c|c|}
\hline \multirow{2}{*}{ Age (years) } & $\mathbf{n ~ ( \% )}$ & Mean $\mathbf{\text { SS }}$ \\
\cline { 2 - 3 } & $\mathbf{3 6 3} \mathbf{( 1 0 0 . 0 )}$ & $\mathbf{4 4 . 2} \pm \mathbf{1 1 . 9}$ \\
\cline { 2 - 3 } & $\mathbf{n}$ & $\mathbf{1}$ \\
\hline Gender & 297 & 81.8 \\
Woman & 66 & 18.2 \\
\hline Male & & \\
Education status & 179 & 49.3 \\
Primary school and below & 123 & 33.9 \\
Secondary school-high school & 61 & 16.8 \\
\hline University & & \\
\hline Working status & 112 & 30.9 \\
Employee and student & 251 & 69.1 \\
Inoperative & & \\
\hline Marital status & 281 & 77.4 \\
Married & 82 & 22.6 \\
Single & & \\
\hline Smoking consumption & 283 & 78.0 \\
None/ Ex smoker (at least 1 year) & 80 & 22.0 \\
Yes & & \\
\hline Childhood obesity & 243 & 66.9 \\
No & 120 & 33.1 \\
\hline Yes & & \\
\hline Obesity in the family & 112 & 30.9 \\
No & 251 & 69.1 \\
\hline Yes & & \\
\hline
\end{tabular}

The average fasting blood glucose was $108.5 \pm 35.9 \mathrm{mg} / \mathrm{dL}$, with the mean $\mathrm{HbAlc}$ of $6.1 \pm 1.0 \%$, total cholesterol average of 211.7 
$\pm 43.2 \mathrm{mg} / \mathrm{dL}, \mathrm{HDL}$ average of $50.1 \pm 11.1 \mathrm{mg} / \mathrm{dL}$, LDL average of $133.4 \pm 37.9 \mathrm{mg} / \mathrm{dL}$, median insulin level of 16.7 (11.5-24.0) $\mu \mathrm{IU} / \mathrm{mL}$, and triglyceride median of 131.0 (94.0-180.0) $\mathrm{mg} / \mathrm{dL}$. HOMA median was 4.2 (2.7-7.0). The median betatrophin levels were found to be $745.8(636.3-935.7) \mathrm{ng} / \mathrm{L}$.

According to Framingham risk scoring, 232 (63.9\%) patients were low-risk, 80 (22.0\%) medium-risk, and 51 (14.1\%) high-risk. According to the PRCAE scoring system, 234 (64.5\%) patients were found to be low-risk, 41 (11.3\%) medium-risk, and $88(24.2 \%)$ high-risk. When the betatrophin levels were compared with the patients who were divided into risk groups according to Framingham and PRCAE risk calculation systems, there was no significant difference between PRCAE risk calculation system subgroups and betatrophin level $(p=0.184)$; while a statistically significant difference was found between Framingham risk calculation system subgroups $(p=0.049)$. When the subgroups were evaluated, it was seen that the difference was significant in transition from the medium-risk group to the high-risk group ( $p=0.029)$. The relationship between the subgroups and betatrophin level of all participants in our study, according to their cardiovascular risk scoring systems, is summarised in Tablell.

Table II: Relationship between cardiovascular risk groups and betatrophin levels of the participants.

\begin{tabular}{|l|c|c|c|}
\hline & $\mathbf{n}(\%)$ & $\begin{array}{c}\text { Median } \\
\text { (25th percentile-75th } \\
\text { percentile) }\end{array}$ & p \\
\hline $\begin{array}{l}\text { Framingham } \\
\text { Low risk }\end{array}$ & $232(63.9)$ & $760.0(645.2-950.1)$ & $0.049^{*}$ \\
Medium risk & $80(22.0)$ & $753.7(649.8-956.3)$ & \\
High risk & $51(14.1)$ & $695.4(599.1-861.2)$ & \\
\hline PRCAE & & $768.9(650.0-752.2)$ & 0.184 \\
Low risk & $234(64.5)$ & $713.4(623.4-905.0)$ & \\
Medium risk & $41(11.3)$ & $711.6(607.7-890.4)$ & \\
High risk & $88(24.2)$ & & \\
\hline
\end{tabular}

A statistically significant negative correlation was found between betatrophin level and fasting triglyceride level in the patients included in the study $(r=-0.166, p=0.001)$. There was no significant relationship between fasting blood glucose, $\mathrm{HbAlc}$, insulin, homeostatic model assessment of Insulin resistance (HOMA-IR), total cholesterol, HDL, LDL levels, and betatrophin levels $(p=0.201, p=0.144, p=0.640, p=0.393, p=$ $0.699, p=0.302, p=0.658$, respectively). The data on the participants' chronic disease status, gender, smoking, drug use, and the degree of obesity detected, and the comparison of betatrophin level are shown in Table III. There was no significant relationship between betatrophin level and age, systolic blood pressure, and diastolic blood pressure in the patients included in the study ( $p=0.269, p=0.107, p=0.256$, respectively). There was no significant relationship between betatrophin level and waist circumference, BMI, body fat mass, and body fat percentage in the patients included in the study $(p=0.226, p=0.473, p=$ $0.778, p=0.111$, respectively).

Table III: Comparison of participants' chronic disease status, gender, smoking, drug use, degree of obesity and betatrophin level.

\begin{tabular}{|c|c|c|}
\hline & $\begin{array}{c}\text { Betatrophin }(\mathrm{ng} / \mathrm{L}) \\
\text { Median } \\
\text { (25th percentile-75th percentile) }\end{array}$ & p \\
\hline $\begin{array}{l}\text { Gender } \\
\text { Woman } \\
\text { Male }\end{array}$ & $\begin{array}{l}757.6(644.0-948.9) \\
705.3(578.4-907.6) \\
\end{array}$ & 0.057 \\
\hline $\begin{array}{l}\text { Smoking } \\
\text { Non-smoking } \\
\text { Smoking } \\
\text { Ex-smoker }\end{array}$ & $\begin{array}{c}742.1(648.5-925.3) \\
732.0(619.8-1027.9) \\
790.4(611.4-937.3)\end{array}$ & 0.913 \\
\hline $\begin{array}{l}\text { Obesity degree } \\
\text { Class } 1 \\
\text { Class } 2 \\
\text { Class } 3\end{array}$ & $\begin{array}{l}788.8(644.6-992.7) \\
741.8(621.5-894.4) \\
726.2(636.9-924.5)\end{array}$ & 0.461 \\
\hline $\begin{array}{l}\text { Diabetes mellitus } \\
\text { Yes } \\
\text { No }\end{array}$ & $\begin{array}{l}721.9(618.0-885.0) \\
762.9(644.6-952.2) \\
\end{array}$ & 0.176 \\
\hline $\begin{array}{l}\text { Hypertension } \\
\text { Yes } \\
\text { No }\end{array}$ & $\begin{array}{l}738.0(639.2-895.3) \\
747.8(635.1-949.2) \\
\end{array}$ & 0.810 \\
\hline $\begin{array}{l}\text { Metabolic syndrome } \\
\text { Yes } \\
\text { No }\end{array}$ & $\begin{array}{l}714.1(618.0-906.0) \\
791.5(656.8-974.7)\end{array}$ & 0.021 \\
\hline $\begin{array}{l}\text { Prediabetes } \\
\text { Yes } \\
\text { No }\end{array}$ & $\begin{array}{l}754.5(634.7-946.5) \\
742.3(636.3-935.2)\end{array}$ & 0.827 \\
\hline $\begin{array}{l}\text { Insulin resistance } \\
\text { Yes } \\
\text { No }\end{array}$ & $\begin{array}{l}737.6(627.8-946.2) \\
759.9(642.7-925.8)\end{array}$ & 0.731 \\
\hline $\begin{array}{l}\text { Use metformin } \\
\text { Yes } \\
\text { No }\end{array}$ & $\begin{array}{l}745.8(617.1-950.4) \\
745.1(645.2-935.3)\end{array}$ & 0.579 \\
\hline $\begin{array}{l}\text { Use insulin } \\
\text { Yes } \\
\text { No }\end{array}$ & $\begin{array}{l}594.5(519.6-874.1) \\
748.8(642.9-946.8)\end{array}$ & 0.013 \\
\hline $\begin{array}{l}\text { Use antilipolytic } \\
\text { Yes } \\
\text { No }\end{array}$ & $\begin{array}{l}697.9(615.1-855.9) \\
758.0(640.0-946.8)\end{array}$ & 0.080 \\
\hline
\end{tabular}

\section{DISCUSSION}

Although there are several studies in the literature comparing betatrophin level with each of the risk factors that increase the risk of CVD one by one, no study has proved the relationship between betatrophin level and cardiovascular risk calculation models. ${ }^{14-17}$ Betatrophin is thought to be valuable in predicting CVD as it is associated with most of the cardiovascular risk factors. ${ }^{15}$

In their study, Leiherer et al. enrolled patients who were referred to coronary angiography consecutively and followed their survival and cardiovascular events with an approximately 8-year follow-up. The incidence of hypertension in patients included in their study was $73.6 \%$ and was similar to the finding of this study. Similar to this study, there was no significant difference in betatrophin level between patients with and without hypertension. As a result of 8 years of follow-up, they found that the survival rate of people with high betatrophin levels without having a cardiovascular event was significantly higher than those with low and moderate betatrophin levels. They found a positive correlation with triglyceride level and a negative correlation with HDLlevel. ${ }^{14}$ 
Abu-Farha et al. conducted a study that found that betatrophin levels increased in individuals with hypertension. ${ }^{15}$ In this study, no significant difference was found between betatrophin levels in individuals with and without hypertension. In another study, Abu-Farha et al. studied patients with and without metabolic syndrome. Betatrophin level was higher in the group with metabolic syndrome. In addition, betatrophin level was found to be positively associated with BMI, triglyceride, LDL, HOMA-IR and fasting blood glucose. ${ }^{16}$ In the present study, betatrophin level was lower in patients with metabolic syndrome compared to patients without metabolic syndrome, and a significant difference was found between them.

Niki et al. in their studies in which they did not include patients with a history of CVD, they detected CAD in 241 (53\%) of 457 patients. They found that the patients with CAD were older, male gender, hypertension, hypertriglyceridemia, diabetes and smoking prevalence higher. They found that betatrophin level was significantly higher in patients with CAD than those without. Although betatrophin level is associated with some cardiovascular risk factors such as diabetes, hypertriglyceridemia, they suggested that it is a significant marker for peripheral artery disease independent of atherosclerotic risk factors. ${ }^{9}$ In the present study, betatrophin level was found to be low in patients with hypertension, male gender and smokers, and the difference was not significant. The difference of the ELISA kit used may have caused this difference. In another study, Niki et al. scanned patients with carotid ultrasound and measured plasma betatrophin levels in 153 patients without known CVD to investigate the relationship between plasma betatrophin level and carotid atherosclerosis. They found that betatrophin level was significantly higher in patients with plaque in the carotid than in patients without. Betatrophin is thought to play a role in atherosclerotic events, but its mechanism is unknown. ${ }^{17}$ It is thought that more comprehensive studies with larger patient populations are required to explain the atherogenic effect of betatrophin.

Fadaei et al. studied 71 patients with known CAD and a control group of 192 patients, and found that serum betatrophin levels were higher in patients with CAD. They observed that the relationship between betatrophin level and CAD was significant in the patient groups after adjustment for age, gender, and BMI. ${ }^{18}$ These studies suggest that betatrophin level may have a role in the pathogenesis of atherosclerosis.

Huang et al. investigated the relationship between CVD and betatrophin in type 2 DM patients. CVD was significantly higher in advanced age and male gender. Betatrophin level was found to be significantly higher in patients with CVD than those without. ${ }^{19}$ In this study, subjects with known CVD were excluded. It was observed that betatrophin level decreased significantly as the patient's risk increased according to the Framingham risk score in individuals without known CVD. Although the increase in the risk score was significantly associated with the decrease in betatrophin level, it was found more prominently among the medium and high-risk groups.
The effect of betatrophin on insulin resistance has not been clearly determined. In some studies, a positive correlation was observed with type 2 diabetes, gestational diabetes and insulin resistance. Xu et al. examined 192 publications in the literature, analysed 6,521 participants, including 1,235 type 2 diabetes, 238 prediabetes, 277 PCOS, 189 obese, and 1,011 metabolic syndromes. They found that six different ELISA kits were used in the studies examined. According to the meta analysis result, although the relationship between betatrophin and insulin resistance was found to be statistically significant, it was thought that there were contradictory results regarding betatrophin, and this heterogeneity might be due to different operating principles of differentELISA kits. ${ }^{20}$

Gomez-Ambrosi et al. investigated the relationship between type 2 DM and obesity and betatrophin level. As in this study, they recorded lower betatrophin levels in males than females. They found that betatrophin level decreased significantly in insulin resistance associated with obesity and obesity. ${ }^{21}$ In this study, as the degree of obesity increases, betatrophin level decreases. Betatrophin levels are found lower in patients with insulin resistance, but the difference was not significant. These differences may be due to different operating principles of differentELISA kits.

In a meta-analysis, investigating the relationship between betatrophin level and obesity conducted by Ye et al. in a total of studies, the results of the studies were heterogeneous. Some studies were positively correlated, some unrelated, some negatively related. Examining the contents of the studies, they found that serum samples were used in some and plasma samples were used in others and the working principles of ELISA kits used were different. It was thought that these situations might create limitations for the studies and be related with inconsistencies in the results. As a result of the analysis, they found a positive relationship between obesity and betatrophin level. ${ }^{22}$

Gestational diabetes and PCOS were excluded because patients with known CVD. Many conditions claimed to be associated with betatrophin levels were excluded, and consequently a population with a relatively low CVD risk was studied. This is one of the limitations of the present study. In addition, it should be kept in mind that a positive or negative relationship may be detected due to the difference in the working principles of ELISA kits. In order to better understand betatrophin, reveal the conditions it is related to, and obtain real outputs, there is need for larger scale studies which excludes methodological factors such as gender, age, $\mathrm{BMI}$, and chronic diseases.

\section{CONCLUSION}

This study revelaed that although a meaningful relationship with the PRCAE risk calculation system has not been revealed, the correlation between Framingham and betatrophin level is promising to be used as a biomarker in predicting CVD risk.

\section{ETHICALAPPROVAL:}

Approval was obtained from the Ethics Committee of University of Health Sciences Kartal Dr. Lutfi Kırdar City Hospital with Ethics 
Committee No. 2019/514/148/31.

\section{PATIENTS' CONSENT:}

Informed consents were obtained from all patients.

\section{CONFLICT OF INTEREST:}

The authors declared no conflict of interest.

\section{AUTHORS' CONTRIBUTION:}

$\mathrm{NH}, \mathrm{HC}, \mathrm{OH}, \mathrm{EES}$ : All have made significant contributions to the concept and design of the study, the collection of data for business analysis and interpretation of data, and preparation of the working draft.

\section{REFERENCES}

1. Evren B, Topaloğlu Ö. Obezitenin medikal tedavisi. Fırat Tıp Derg. 2018; 23: p.72-77.

2. Lavie CJ, McAuley PA, Church TS, Milani RV, Blair SN. Obesity and cardiovascular diseases: Implications regarding fitness, fatness and severity in the obesity paradox. J Am Coll Cardiol 2014; 63(14): p.1345-54. doi: 10.1016/j.jacc. 2014.01.022.

3. Eray A, Ateş E, Set T. Yetişkin Bireylerde Kardiyovasküler Hastalık Riskinin Değerlendirilmesi. Türk Aile Hek Derg 2018; 22(1): p.12-19. doi: 10.15511/tahd.18.00112.

4. Tekkeşin N, Kılınç C, Ökmen AŞ. Türk Erişkinlerde Framingham Risk Faktörlerinin Araştırılması. Klinik ve Deneysel Araştırmalar Derg 2011; 2(1): p. 42-49. doi: 10.5835/jecm.omu.30.s1.007.

5. Preiss D, Kristensen SL. The new pooled cohort equations risk calculator. Can J Cardiol 2015; 31(5): p. 613-9. doi: 10.1016/j.cjca.2015.02.001.

6. Tseng $\mathrm{YH}, \mathrm{Yeh} \mathrm{YH}$, Chen WJ, Lin $\mathrm{KH}$. Emerging regulation and function of betatrophin. Int J Mol Sci. 2014; 15(12): p. 23640-57. doi: 10.3390/ijms151223640.

7. Xu F, Chen Y, Wang N, Sun K. Bacteria-derived recombinant human angptl8/betatrophin significantly increases the level of triglyceride. Protein J 2019; 38(4): p. 472-8. doi: 10. 1007/s10930-019-09825-8.

8. Luo M, Peng D. ANGPTL8: An Important regulator in metabolic disorders. Front Endocrinol (Lausanne) 2018; 9: p. 169. doi: 10.3389/fendo.2018.00169.

9. Niki H, Kishimoto Y, Ibe S, Saita E, Sasaki K, Miura K, et al. Associations between plasma betatrophin levels and coronary and peripheral artery disease. J Atheroscler Thromb 2019; 26(6): p. 573-581. doi: 10.5551/jat.46508.

10. Sabuncu T. Bariatric surgery guideline. Society Endocrino Metabolism Turkey 2019; p:11.

11. Kültürsay H. Kardiyovasküler hastalık riski hesaplama yöntemleri. Türk Kardiyol Dern Arş 2011; 39:6-13. doi: 10.5543/tkda.2011.kultursay.

12. Goff DC, Lloyd-Jones DM, Bennett G, Coady S, D'Agostino RB, Gibbons R, et al. 2013 ACC/AHA guideline on the assessment of cardiovascular risk: A report of the American College of Cardiology/American Heart Association task force on practice guidelines. Circulation 2014; 129 (Suppl2): S49-73. doi: 10.1161/01.cir.0000437741.48606.98.

13. Natascha W. Applications of the Eppendorf $5.0 \mathrm{~mL}$ system. Applicatıon Note No. 265. 2013; June.

14. Leiherer A, Ebner J, Muendlein A, Brandtner EM, Zach C, Geiger K, et al. High betatrophin in coronary patients protects from cardiovascular events. Atherosclerosis 2020; 293:62-8. doi: 10.1016/j.atherosclerosis.2019.11.011.

15. Abu-Farha M, Cherian P, Qaddoumi MG, AlKhairi I, Sriraman $D$, Alanbaei $M$, et al. Increased plasma and adipose tissue levels of ANGPTL8/Betatrophin and ANGPTL4 in people with hypertension. Lipids Health Dis 2018; 17(1):p.35. doi: 10.1186/s12944-018-0681-0.

16. Abu-Farha M, Abubaker J, Al-Khairi I, Cherian P, Noronha F, Kavalakatt $\mathrm{S}$, et al. Circulating angiopoietin-like protein 8 (betatrophin) association with HsCRP and metabolic syndrome. Cardiovasc Diabetol 2016; 15:p.25. doi: 10.1186/ s12933-016-0346-0.

17. Niki H, Kishimoto $Y$, Saita E, Ohmori R, Kondo K, Momiyama Y. Plasma betatrophin levels and carotid atherosclerosis. Dis Markers 2019; 2019:4214650. doi: 10.1155/2019/ 4214650.

18. Fadaei R, Shateri H, DiStefano JK, Moradi N, Mohammadi M, Emami $F$, et al. Higher circulating levels of ANGPTL8 are associated with body mass index, triglycerides, and endothelial dysfunction in patients with coronary artery disease. Molecular and Cellular Biochemistry 2020; 469(1-2): 29-39. doi: 10.1007/s11010-020-03725-7.

19. Huang $Y$, Fang $\mathrm{C}$, Guo $\mathrm{H}, \mathrm{Hu}$ J. Increased angiopoietin-like protein 8 levels in patients with type 2 diabetes and cardiovascular disease. Diabetes Res Clin Pract 2016; 120:p. 229-31. doi: 10.1016/j.diabres.2016.08.017.

20. Xu J, Lin Y, Zhou H, Zhao L, Xiang G. The correlation between circulating betatrophin and Insulin resistance in general population: A meta-analysis. Horm Metab Res 2017; 49(10):p. 760-771. doi: 10.1055/s-0043-108911.

21. Gomez-Ambrosi J, Pascual E, Catalán V, Rodríguez A, Ramírez B, Silva C, et al. Circulating betatrophin concentration sare decreased in human obesity and type 2 diabetes. J Clin Endocrinol Metab 2014; 99(10): p. E2004-9. doi: 10.1210/jc.2014-1568.

22. Ye J, Qin Y, Wang D, Yang L, Yuan G. The relationship between circulating angptl8/betatrophin concentrations and adult obesity: A meta-analysis. Disease markers 2019; p.5096860. doi: 10.1155/2019/5096860. 